\title{
A ECONOMIA POLÍTICA DO MODELO ECONÔMICO CHINÊS: O ESTADO, O MERCADO E OS PRINCIPAIS DESAFIOS
}

\author{
Alexandre Queiroz Guimarães
}

\begin{abstract}
RESUMO
O artigo explora algumas características do modelo chinês a partir de sua particularidade institucional, a relação entre o Estado e o mercado. Pretende-se esclarecer as razões dos bons resultados econômicos, destacar o papel essencial da variável internacional e apontar os principais desafios enfrentados pelo modelo chinês. Uma preocupação central é destacar as implicações, realizações e riscos de uma combinação muito particular entre o mercado e o Estado, tocando em um tema caro à Economia Política desde Adam Smith. Para esse intuito, o artigo dialoga com teorias da Economia Política e do desenvolvimento econômico, com destaque para o debate sobre os estados desenvolvimentistas. Argumenta-se que o sucesso do milagre chinês está relacionado à liberalização das forças de mercado, mas deve-se também ao papel do Estado Desenvolvimentista, que desempenhou um papel importante na transição para a economia de mercado e vem contribuindo significativamente para o fortalecimento da capacidade produtiva e tecnológica. Entretanto, a falta de demarcação entre o Estado e o mercado também implica dificuldades, que se manifestam na intervenção excessiva do partido e nas deficiências do sistema financeiro e do sistema de direitos de propriedade. De um lado, a economia beneficia-se da força do Estado e das medidas adotadas para fortalecer sua posição internacional. De outro, há tensões entre uma economia mais complexa e uma estrutura institucional muito específica. Outro ponto explorado são os esforços adotados para fortalecer a capacidade industrial e tecnológica, perguntando-se sobre a efetividade da política industrial no estágio atual do capitalismo. Enfim, o artigo trabalha outros desafios do modelo chinês, inclusive na área social, apontando como vêm sendo enfrentados.
\end{abstract}

PALAVRAS-CHAVE: China; instituições; desenvolvimento; Estado desenvolvimentista; Economia Politica.

\section{INTRODUÇÃO ${ }^{1}$}

Desde que iniciou as reformas internas, em 1978, a China vem crescendo a taxas elevadas, próximas, na média, a $9 \%$ ao ano ${ }^{2}$. Ao contrário do que ocorreu em outros países que possuíam uma economia planificada, como a Rússia e o Leste Europeu, a transição chinesa foi acompanhada por

\footnotetext{
$1 \mathrm{O}$ autor agradece ao Fundo de Incentivo à Pesquisa da Pontifícia Universidade Católica de Minas Gerais (PUC$\mathrm{MG)}$ pelo financiamento concedido, bem como aos pareceristas anônimos da Revista de Sociologia e Política pelos comentários feitos ao presente artigo.

2 Com exceção de 1989, ano em que o produto interno bruto (PIB) não cresceu, e 1997, quando houve uma desaceleração, taxas elevadas de crescimento foram alcançadas em todo o período (WORLD BANK, 2011).
}

melhoria nas condições materiais e sociais da população. Estimativas do Banco Mundial apontam que, entre 1978 e 2004, 500 milhões de pessoas teriam deixado a linha de pobreza (medida por US\$ 1 por dia), com a proporção de pobres caindo de 60\%, em 1978, para 10\% em 2004 (DOLLAR, 2007, p. 2). Nesse mesmo período, a renda média da população quadruplicou, atingindo em 2010 uma renda nominal per capita, ponderada pela paridade do poder de compra (PPP), de US\$ 7536 (WORLD BANK, 2011). Ao mesmo tempo, a economia chinesa vem avançando, tornando-se a manufatura do mundo em vários setores e crescendo a participação na exportação de produtos elaborados e tecnologicamente intensivos.

O objetivo deste artigo é explorar certas características do modelo econômico chinês. Pretende-se esclarecer as razões dos bons 
resultados econômicos, destacar o papel essencial da variável internacional e apontar os principais desafios enfrentados pelo modelo chinês. Uma preocupação central é destacar as implicações, realizações e riscos de uma combinação muito particular entre o mercado e o Estado, tocando em um tema caro à Economia Política desde Adam Smith. Para esse intuito, o artigo dialoga com teorias da Economia Política e do Desenvolvimento Econômico, com destaque para o debate sobre os "Developmental States" (WORLD BANK, 1993; EVANS, 2004; NOLAN, 2004; CHANG, 2006)33.

Um ponto inicial consiste em indagar o que leva a China a apresentar taxas de crescimento tão altas. Martin Wolf, articulista do jornal Financial Times, pergunta: "Há algo excepcional no crescimento chinês?" (WOLF, 2009). Wolf compara o desempenho chinês com aquele verificado no Japão, na Coreia do Sul e em Taiwan nos seus "milagres econômicos". De 1978 a 2003, o PIB per capita chinês cresceu $6,1 \%$ ao ano, abaixo do crescimento japonês no período 1950 a 1973 (8,2\% ao ano). Os resultados para a Coreia do Sul (1960 a 1990) e para Taiwan (1958 a 1987) foram, respectivamente, $7,6 \%$ e $7,1 \%$ ao ano.

O ponto destacado por Wolf refere-se à relação entre o grau de atraso econômico e as taxas de crescimento: quando os países são mais atrasados, embora não tão atrasados, eles beneficiam-se das ideias e das técnicas disponíveis em outros países. Tendem também a beneficiar-se da transferência de trabalhadores de atividades de baixa produtividade, como a agricultura de subsistência, para outras mais produtivas na indústria e no setor serviços. Além disso, o capital é escasso e tem alta produtividade, abrindo muitas oportunidades para a expansão do investimento. A partir dessas considerações, Wolf conclui que o crescimento chinês não é excepcional, exceto pela escala e pelo tamanho da população envolvida.

Um ponto merece destaque: todos os países supracitados são exemplos de sucesso. Os números seriam bem diferentes se a amostra incluísse outros países da Ásia e da América Latina. Isso implica entender o que permitiu à China replicar as experiências bem-sucedidas, enquanto

\footnotetext{
3 A seção IV utiliza aspectos teóricos das teorias sobre "capacidade do Estado" e sobre os "developmental states" para entender aspectos centrais do modelo chinês.
}

a regra nas estratégias de desenvolvimento foi, durante muitas décadas, o sucesso moderado ou o fracasso. O ponto cresce em importância quando se considera que as experiências de transição de economias de planejamento central para economias de mercado tiveram resultados muito inferiores, tendo produzido, na maioria dos casos, desestruturação econômica, queda do PIB e altos custos sociais (WHITE, 2000; NOLAN, 2005).

\section{FUNDAMENTOS DO DESENVOLVIMENTO ECONÔMICO E O CASO CHINÊS}

O caminho para o desenvolvimento não é tão simples como apontado por Adam Smith quando ele dizia que "pouco mais é necessário para conduzir uma nação do mais baixo barbarismo até o mais elevado grau de opulência do que paz, impostos razoáveis e uma administração tolerável da justiça; tudo o mais sendo trazido pelo curso natural das coisas"4. Além da justiça e da segurança, vários pré-requisitos são necessários para que o "curso natural das coisas", ou seja, as forças de mercado, produzam resultados favoráveis. Infraestrutura de transportes e energia, sistema financeiro avançado, capacidade empresarial e técnica e contexto de estabilidade são alguns requisitos necessários. O cumprimento dessas funções demanda certo grau de capacidade estatal, que tende a ser maior quão mais retardatário é o processo de industrialização (CHANG, 2004; EVANS, 2004).

O sucesso chinês aparece, inicialmente, na bem-sucedida transição para uma economia de mercado. O processo de "dual track", nome dado à forma como os chineses introduziram as forças de mercado sem abandonar o planejamento, a liberalização da agricultura, o estímulo às empresas rurais e as reformas dos sistemas empresarial e financeiro, ilustra a capacidade das lideranças chinesas em conduzir o processo. A transição conduziu-se de modo que a introdução das forças de mercado fosse acompanhada de medidas visando à correção das eventuais falhas de mercado. O contraste com outros processos de transição, principalmente aquele verificado na Rússia, foi enorme (WHITE, 2000; NOLAN, 2005). As autoridades, recusando propostas

\footnotetext{
4 Passagem extraída dos rascunhos da Riqueza das Nações (Smith apud FONSECA, 1993).
} 
construtivistas $^{5}$, optaram por "cruzar o rio tateando as pedras", de modo a garantir os prérequisitos necessários ao êxito do novo sistema econômico. Ao mesmo tempo, o governo preservou a capacidade de intervenção, que se mostrou fundamental para proteger os grupos vulneráveis e os perdedores com o processo de mudança.

A construção de capacidade empresarial foi essencial. O governo optou por reformar gradualmente as empresas estatais, ampliando a autonomia, mas reforçando a capacidade de supervisão. A reforma foi feita em etapas, ampliando o papel das forças de mercado, valorizando a eficiência e buscando aumentar a autonomia e a transparência. Um processo brusco de privatização foi evitado. Na década de 1990, as empresas foram listadas no mercado de capitais, como forma de ampliar a transparência e de privatizar parte das empresas. Em todo o processo, as lideranças estimularam a formação de grandes conglomerados capazes de enfrentar a competição internacional. Assim, apesar das dificuldades que ainda persistem ${ }^{6}$, é inegável o sucesso em produzir empresas capazes de atuar de acordo com os princípios de uma economia de mercado (RALSTON et alii, 2006; NAUGHTON, 2007).

Paralelamente à reforma empresarial, o governo reformou o sistema financeiro. Os bancos foram separados em bancos de políticas e bancos comerciais. Os últimos deveriam atuar segundo os critérios de mercado. O intuito da reforma foi impedir que o sistema financeiro continuasse a financiar empresas estatais ineficientes, assim como melhorar a capacidade de avaliação de riscos e de alocação dos recursos para os setores de maior produtividade. Apesar dos avanços, o sistema financeiro ainda é muito atrasado, sendo apontado como um dos elos frágeis do modelo chinês (NOLAN, 2004; PEI, 2006).

\footnotetext{
5 O termo "construtivista" faz menção às críticas de Hayek às experiências mirabolantes de inovação social, muitas tendo produzido resultados desastrosos. Os chineses já haviam vivido algo nessa direção com o "Grande Salto à Frente", que matou milhões de pessoas.

6 Entre as dificuldades incluem-se o atraso em termos de governança corporativa e a forte intervenção estatal, o que, em certos casos, leva os dirigentes a privilegiarem considerações de outra ordem e a afastarem a empresa do objetivo de aumentar a eficiência. O ponto é explorado adiante.
}

O sucesso da intervenção também se refletiu na condução da política econômica. Em contraste com outras experiências de transição, a inflação foi mantida sob controle, medida que teve efeitos positivos sobre as taxas de poupança e de investimento (NAUGHTON, 2007). A política de comércio exterior foi bem conduzida, com a manutenção de uma taxa de câmbio desvalorizada que favoreceu as exportações. Por sua vez, a criação das zonas econômicas especiais (ZEEs) permitiu o acesso a recursos e à tecnologia estrangeiros. Ambas as políticas ajudaram a China a driblar os constrangimentos do balanço de pagamentos, ao mesmo tempo em que promoviam o crescimento da demanda e do PIB.

O desempenho foi também favorecido pelas condições de infraestrutura, indicativo da aptidão do Estado em prover bens públicos essenciais. A China destaca-se por possuir alguns dos maiores portos do mundo e pela capacidade de movimentar contêineres a baixos custos. O país também possui uma extensa malha ferroviária, que vem sendo expandida e foi fortemente estimulada recentemente ${ }^{7}$. A rede de transportes e as facilidades de logística contribuem para a redução dos custos e para reforçar a posição da China como elo estratégico para a otimização das cadeias produtivas internacionais. Outro requisito é a capacidade educacional e técnica. Há indicadores que colocam a China à frente de outros países emergentes $^{8}$, diferença que é muito pronunciada nas províncias mais avançadas ${ }^{9}$. Além disso, há um grande número de laboratórios, centenas de milhares de cientistas e engenheiros são formados anualmente ${ }^{10}$ e centenas de milhares de estudantes saem para estudar no exterior. Como conseqüência, a mão de obra é abundante também

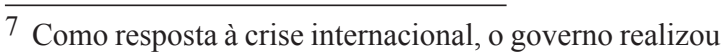
investimentos de US\$ 500 bilhões, que incluem projetos ambiciosos visando expandir a rede ferroviária (ANTUNES, STEFANO \& MARANHÃO, 2009).

8 Segundo Stephen Roach (2011), "a alfabetização de adultos está acima de $95 \%$ e as taxas de matrícula no ensino secundário passam de $80 \%$ ".

9 Em testes internacionais em matemática, ciência e leitura, a província de Shangai atingiu a primeira posição, seguida por Cingapura, Coreia e Taiwan (JACQUES, 2012).

10 O número de graduados teria passado de $950 \mathrm{mil} \mathrm{em}$ 2000 para 4,5 milhões em 2007 (idem).
} 
em setores que exigem certa qualificação, ampliando a atratividade da China para investimentos em setores mais elaborados ${ }^{11}$.

É à luz desses requisitos e fundamentos que se deve destacar o papel dos fatores de produção. Não há como descrever o milagre chinês sem enfatizar a mão de obra barata e de certa qualidade. A grande proporção da população rural, alta para o nível de renda per capita, propicia um exército quase inesgotável de mão de obra que tende a impedir que os salários subam significativamente, pelo menos nos tipos de trabalho menos qualificados (NOLAN, 2004) ${ }^{12}$. Aos baixos salários somam-se os baixos encargos trabalhistas, as longas horas de trabalho e a grande flexibilidade do mercado de trabalho, reforçando as vantagens comparativas advindas do fator trabalho.

À abundância de mão de obra adicionam-se as altas taxas de investimento, respaldadas por altas taxas de poupança das famílias, investimentos das empresas estatais e grande atração de capital estrangeiro. Em um país com oferta abundante de mão de obra, a mobilização de capital torna-se essencial para a velocidade do crescimento e para o êxito do processo de catch up. Deve-se destacar que a China tem investido mais de $40 \%$ do PIB, taxa elevada mesmo quando comparada àquelas verificadas nos outros milagres econômicos ${ }^{13}$.

Enfim, outros elementos contribuem para os resultados alcançados. Por enquanto, vale destacar a influência da estrutura etária, dado que algo como $70 \%$ da população encontrava-se na faixa etária de 15 a 64 anos e, portanto, em idade ativa (AMARAL, 2005). Outro ponto é o crescimento do mercado interno, que em certos setores responde por grande parte do acréscimo da

\footnotetext{
11 Portanto, a China atrai investimentos não apenas devido à mão de obra barata e ao tamanho do mercado consumidor. Diversos fatores distinguem-na de outros países que apresentam baixos custos salariais.

12 Mudanças vêm ocorrendo nas províncias mais ricas, com a eclosão de greves, aumentos de salários e revisão dos direitos trabalhistas. Na impossibilidade de competir com baixos custos salariais, a estratégia passa a ser fomentar a capacidade produtiva em nichos mais elaborados (idem).

13 Em níveis similares de renda per capita, o Japão investia $32 \%$ e a Coreia do Sul, $30 \%$ do PIB (WOLF, 2009). O excesso de investimento também pode acarretar problemas, ponto explorado adiante.
}

demanda mundial. Esse resultado dá ao governo grande capacidade de negociar com o capital estrangeiro e de exigir condições para a sua entrada, incluindo a transferência de tecnologia. Além disso, o mercado interno representa uma base de expansão para as empresas chinesas, que obtêm os ganhos de escala que elevam a capacidade para competir no exterior.

\section{A CHINA E O EXTERIOR - O CONTEXTO INTERNACIONAL E AS PARTICULA- RIDADES DO MODELO CHINÊS}

A China é particular por uma série de fatores, relacionados a seu tamanho, taxa de crescimento e posição geopolítica. Essas particularidades, bem utilizadas pelas lideranças, vêm dando ao país certos graus de liberdade que não são usualmente disponíveis aos demais países. Isso se reflete na autonomia de sua política econômica, assim como na capacidade de negociar com outros países e com as empresas multinacionais. A base da autonomia da China está fortemente relacionada às realizações de seu comércio exterior, uma vez que a dependência de recursos externos poderia implicar ingerência nas políticas internas. Na década de 1970, negociações relacionadas ao processo de aproximação com os Estados Unidos propiciaram condições favoráveis de financiamento e o acesso privilegiado ao mercado americano, tendências que foram combinadas com políticas voltadas a atrair capital estrangeiro e a estimular as exportações.

Contrariamente a outros países de industrialização tardia, a promoção do comércio exterior foi um componente essencial do desenvolvimento chinês. Antes das reformas, o comércio internacional desempenhava papel insignificante. A China era um país muito fechado e não adotava políticas voltadas a promover as vantagens comparativas ${ }^{14}$. As reformas que ocorreram a partir de 1978 modificaram esse quadro e as operações de comércio exterior passaram a seguir as orientações de mercado. Tarifas e barreiras não tarifárias foram reduzidas, de modo que no início da década de 1990 a China já apresentava um grau de proteção inferior a muitos países em desenvolvimento ${ }^{15}$. Inúmeras medidas promo-

\footnotetext{
14 A pauta de exportações concentrava-se em recursos naturais, contendo muitos produtos que constituem hoje a base das importações chinesas.
} 
veram a liberalização do comércio exterior, apesar de o controle estatal e de regimes especiais terem sido preservados em setores considerados estratégicos ${ }^{16}$ (LARDY, 2002).

A liberalização comercial foi acompanhada pelo rápido crescimento das exportações. Estas foram favorecidas principalmente por duas políticas: a criação das zonas econômicas especiais (ZEEs) e a política cambial. Em um momento em que a China iniciava a transição para uma economia de mercado, as ZEEs, ao oferecerem uma série de facilidades, foram fundamentais para a atração de firmas estrangeiras, voltadas preponderantemente para a exportação ${ }^{17}$. A manutenção do câmbio desvalorizado foi também essencial. Em 1982, a taxa de câmbio foi desvalorizada de 1,5 para 2,8 remimbis por dólar. Desvalorizações sucessivas seguiram-se, de modo que em 1995 a taxa cambial flutuava em torno de 8,3 remimbis por dólar. Segundo estimativas do Fundo Monetário Internacional (FMI), a moeda chinesa teria perdido, entre 1980 e 1995, 70\% do seu valor (idem). A despeito de pressões internacionais, as lideranças chinesas insistiram em manter o câmbio desvalorizado, pois consideravam a promoção das exportações um componente essencial de uma estratégia voltada a reduzir a pobreza. Apenas a partir de 2005, em face das pressões inflacionárias acarretadas pela acumulação de reservas, o governo passou a deixar a moeda valorizar-se, e em ritmo gradual, direção reforçada em 2010.

Como conseqüência, as exportações entre 1984 e 1995 cresceram 17\% ao ano, passando de US\$ 27 bilhões para US \$148,8 bilhões. A participação do comércio exterior no PIB, que era de apenas 10\% em 1978, atingiu 44\% em 1995 (idem). O crescimento continuou na década de 1990 e as exportações atingiram US\$ 266 bilhões em 2001. Após a entrada da China na Organização Mundial do Comércio (OMC), consumada em 2001, houve nova aceleração, de modo que, em 2007, a China

\footnotetext{
15 Em 1992, 95\% dos bens importados apresentavam preços domésticos similares aos preços internacionais

16 O processo de liberalização foi substancial, mantendose o controle apenas sobre uma gama limitada de bens, que incluía grãos, petróleo, vegetais, tabaco, fertilizantes e algodão.

17 As ZEEs chinesas eram muito maiores do que aquelas introduzidas em outros países asiáticos.
}

exportava US\$ 1,2 trilhão, tendo acumulado reservas de US\$ 1,5 trilhão (CUNHA, 2008). Em 2011, as mesmas somavam US\$ 3,1 trilhões (JACQUES, 2012).

Inicialmente, as exportações avançaram principalmente nos setores intensivos em mão de obra. As exportações de produtos têxteis passaram de US\$ 2,54 bilhões em 1980 para US\$ 12,8 bilhões em 1998, enquanto as exportações de roupas e confecções aumentaram de US\$1,48 bilhão para US\$ 27,1 bilhões. As exportações de calçados saltaram de US\$ 173 milhões em 1980 para US\$ 8,4 bilhões em 1998, enquanto as exportações de brinquedos cresceram de US\$ 71 milhões para US\$ 5,1 bilhões. Em 1998, a China já respondia por $8,5 \%$ das exportações mundiais de têxteis, $16,7 \%$ de confecções, $17,9 \%$ de brinquedos e $20,7 \%$ de calçados, parcelas que continuaram crescendo (LARDY, 2002). Estimativas recentes apontavam que a China era responsável por dois terços da produção mundial de sapatos, brinquedos, fornos de micro-ondas e máquinas de fotocópias, além de metade da produção mundial de tocadores de DVD, máquinas digitais e têxteis (JACQUES, 2012, p. 185).

Outro componente foi o crescimento do investimento estrangeiro. Parte significativa desse investimento foi realizada por firmas asiáticas, incluindo firmas japonesas, que buscavam neutralizar os efeitos do yen valorizado, e empresas de Hong Kong, Taiwan e Coréia do Sul (PEMPEL, 2005). Tal tendência acelerou-se na década de 1990, tornando a China grande produtor e exportador de produtos eletrônicos e de tecnologia da informação. As firmas de Taiwan, por exemplo, transferiram para a China grande parte da produção de monitores, placas-mãe e teclados para computador $^{18}$ (LARDY, 2002). Como resultado, as exportações de produtos eletrônicos de alta tecnologia aumentaram a participação de $7 \%$ do total das exportações, em 1990, para 37\% em 2005 (CUNHA, 2008, p. 15).

Deve-se destacar o forte conteúdo regional no processo de desenvolvimento chinês. A atração de empresas dos países vizinhos teve impactos significativos no desenvolvimento da indústria

18 Estimativas recentes destacam que $80 \%$ das placasmãe, $70 \%$ dos computadores e $68 \%$ dos monitores de firmas taiwanesas eram feitos na China. 
chinesa e no desempenho exportador. Por sua vez, a ascensão da China e o reforço dos laços produtivos tiveram impacto nas relações produtivas e comerciais de toda a região. Houve forte crescimento do comércio intrarregional, sendo que as exportações intrabloco passaram de $37 \%$ do total, em 1985, para 55\% em $2005^{19}$. Grande parte desse crescimento é atribuída a operações intrafirma, com venda de componentes e equipamentos para a China, que se especializa na montagem e na exportação dos produtos. Estimativas do Banco Mundial apontam que 55\% das exportações da China em 2005 eram feitas por multinacionais a partir da importação de componentes e montagem em território chinês (idem, p. 14-15).

Um aspecto a destacar-se é que graças aos baixos custos e ao amplo mercado, a China configura-se como localização obrigatória das decisões produtivas das grandes empresas multinacionais. Muitas empresas transferem para a China etapas produtivas menos complexas e intensivas em trabalho, aproveitando os baixos custos, de modo que em muitos setores o crescimento das exportações foi acompanhado de baixo valor agregado. Há, no entanto, exemplos que apontam para outra direção, o que é favorecido por políticas voltadas a estimular a produção de componentes e a adicionar valor no próprio país. Além disso, há evidências de que a pressão para baixar os custos tem feito que empresas multinacionais terceirizem mesmo etapas mais complexas, dependentes de mão de obra com maior qualificação, como desenho, engenharia e Pesquisa e Desenvolvimento (P\&D), o que tem proporcionado à China ganhos em termos de absorção de tecnologia e especialização em setores avançados (NAUGHTON, 2007, p. 371; GEREFFI, 2009 $)^{20}$. Em terceiro lugar, não se podem negligenciar os impactos da transferência de tecnologia e de técnicas de gestão, efetivados, em muitos casos, por meio de práticas de joint ventures entre empresas estrangeiras e firmas locais.

\footnotetext{
19 Expansão similar à verificada em blocos regionais como a União Europeia e o Tratado Norte-Americano de LivreComércio (Nafta).

20 Um bom exemplo é o setor de semicondutores e o de circuitos integrados.
}

Um ponto essencial é o impacto desse conjunto de características para a autonomia na condução da política econômica, permitindo à China escapar a muitos constrangimentos e pressões internacionais. Isso se reflete não apenas na política cambial, mas também no ritmo de abertura financeira, livrando o país dos efeitos devastadores da crise asiática de 1997 e da crise mundial de 2008-200921. É essa posição internacional, fundada na força do seu mercado interno, que permite à China enquadrar o capital estrangeiro, conseguindo obter em um contexto bem diferente aquilo que o Japão e a Coréia do Sul obtiveram no contexto de aquiescência norte-americana durante a Guerra Fria. A posição chinesa tende também a ser fortalecida pelo impacto de sua economia no aumento da produtividade global, no crescimento econômico e na recuperação de vários países. Inclui-se a relação simbiótica desenvolvida com os Estados Unidos, cujos interesses são promovidos pela importação de produtos baratos, pelo acesso de suas firmas ao mercado chinês e pela aquisição de títulos do Tesouro pelo governo chinês ${ }^{22}$.

A questão a destacar-se é a capacidade de preservar a autonomia na condução da política de desenvolvimento. A China vem conseguindo adotar uma estratégia em que a introdução das forças de mercado, a promoção do comércio e a atração de capital estrangeiro vêm sendo combinados com a capacidade de moldar certas variáveis na direção da promoção do que se considera o interesse nacional. Apesar de a entrada na OMC ter implicado concessões e o abandono de certos instrumentos, outras formas de intervenção foram introduzidas ou reforçadas. A atuação de estrangeiros no comércio exterior e no doméstico foi liberalizada, e o governo abriu mão tanto de práticas voltadas a favorecer fornecedores locais, como da exigência de quotas de exportações para firmas estrangeiras. Mas o governo continua a conceder incentivos à transferência de tecnologia,

21 Devido ao controle de capitais, a China preservou a estabilidade de sua moeda, a despeito de turbulências como a crise asiática. A estabilidade do yuan tem sido um contraponto à volatilidade do yen, dando vantagens à China na luta pela maior influência regional (MEDEIROS, 2004, p. 166).

22 A China, por sua vez, é dependente do acesso ao grande mercado norte-americano. 
enquanto argumentos como a presença de "setores sensíveis" e de "segurança nacional" são utilizados para regular a entrada do capital estrangeiro e para perseguir objetivos de política industrial (CUNHA \& ACIOLY, 2009).

A posição chinesa e seu alto poder de barganha têm sido reforçados por diversas iniciativas de política externa. Essas se orientam, inicialmente, pela direção de fortalecer os vínculos econômicos, principalmente com os países vizinhos, visando torná-los mais dependentes economicamente. Dentro dessa direção, a China vem avançando na assinatura de acordos de livre comércio com vários países, em que demonstra alta propensão a fazer concessões, grande diferença em relação ao Japão. Além disso, a China vem expandindo o seu aporte de ajuda a outros países, que teria passado de 260 milhões, em 1993, para 1,5 bilhões em 2004. Em países como Filipinas, Indonésia, Laos, Camboja e Mianmar, a ajuda chinesa passou a ser bem superior à concedida pelos Estados Unidos (JACQUES, 2012).

A partir da década de 1990, a estratégia chinesa passou a incluir a participação na Associação de Nações do Sudeste Asiático (Asean) e em outras instâncias regionais, assim como em iniciativas diplomáticas que incluíram a cooperação para enfrentar o terrorismo e as negociações para reduzir a capacidade nuclear da Coréia do Norte. Nesses movimentos, a China vem demonstrando uma enorme cautela e recusando assumir a busca de liderança; uma forma de não assustar os parceiros, além de evitar maiores conflitos com os Estados Unidos (idem).

É importante destacar que o Leste e o Sudeste asiáticos vêm passando, desde a crise de 1997, por grandes mudanças, que incluem a adoção de medidas na direção de fomentar uma maior integração institucional entre os países. Há o objetivo de desenvolver mecanismos de cooperação econômica e financeira, visando reduzir a dependência dos Estados Unidos e do Fundo Monetário Internacional (FMI), que se mostrou perniciosa nos eventos que se seguiram à crise de 1997. As iniciativas incluíram a criação de um fundo para oferecer linhas de crédito em moedas locais, a fim de socorrer países em dificuldades. Em 2005, a China exerceu papel proeminente na organização de uma cúpula em Chiang Mai, Tailândia, voltada para avançar medidas nessa direção (PEMPEL, 2005; CUNHA,
2008, p. 17).

A partir de 2008, em função da crise mundial e da melhor posição de sua economia, a China, detentora de grandes reservas internacionais, abandonou uma posição defensiva e tem criticado o deficit dos Estados Unidos no balanço de pagamentos e o excesso de dólares na economia mundial. Além disso, a crise tem permitido à China aprofundar suas estratégias de investimento no exterior $^{23}$ e de acordos para a obtenção de matérias-primas ${ }^{24}$. Em face da crise dos principais competidores, a posição chinesa tem se fortalecido significativamente, ampliando os vínculos econômicos em várias partes do globo (JACQUES, 2012).

\section{O MODELO ECONÔMICO CHINÊS: UMA COMBINAÇÃO PARTICULAR ENTRE O MERCADO E O ESTADO}

O sucesso da economia chinesa está muito relacionado à promoção das forças de mercado, bem ilustrada pela liberalização da agricultura, pela permissão para o funcionamento das empresas rurais, pela liberalização do comércio exterior e pelas reformas do sistema empresarial e financeiro. Tais medidas despertaram o potencial para o empreendedorismo e permitiram equacionar as dificuldades econômicas vigentes durante o período de planejamento central. Além disso, favoreceram o direcionamento da economia para os setores de maior produtividade, permitindo a exploração de vantagens comparativas.

No entanto, a transição bem-sucedida para uma economia de mercado dependeu também das características de suas lideranças e de sua burocracia, capazes de prover os bens públicos, produzir um contexto de estabilidade e garantir a preservação de estabilidade social. À semelhança de outros estados desenvolvimentistas, a China vem combinando forte intervenção estatal com a

23 Uma estratégia comum vem sendo o uso das reservas internacionais para adquirir empresas em países desenvolvidos. A produção é transferida para a China, mas os departamentos responsáveis pela pesquisa, pelo marketing e fortalecimento da marca e pela distribuição são preservados nos países de origem (O ENIGMA DA CHINA, 2005, p. 2).

24 Um ótimo exemplo são as relações desenvolvidas com países da África, em que investimentos e ajuda financeira vêm sendo trocados pelo acesso ao petróleo e a matériasprimas. 
preservação de bons fundamentos econômicos, incluindo o controle da inflação e a adoção de taxas de câmbio favoráveis às exportações (WORLD BANK, 1993).

Como um caso típico de Developmental State, o Estado chinês transcende amplamente as funções consideradas consensuais pelos economistas: provisão de bens públicos e correção de falhas de mercado. Sua ação está ancorada em políticas voltadas a proteger a indústria nacional, moldar a entrada do capital estrangeiro, induzir a formação de joint ventures e obter condições favoráveis para a transferência de tecnologia. Inspirado no modelo japonês, o governo não mede esforços para produzir grupos empresariais com capacidade tecnológica e competitiva, dado que considera precondição para o poder internacional do país. Uma especificidade da China é a capacidade de fazer essa intervenção em um momento do capitalismo menos permissivo à intervenção estatal, como explorado na seção anterior ${ }^{25}$.

Deve-se destacar o amplo esforço do Estado chinês em promover o desenvolvimento industrial. A proteção ao mercado interno, a oferta de financiamento e o estímulo ao desenvolvimento tecnológico, entre outras medidas, auxiliaram as empresas chinesas a projetar-se no mercado e a ampliar as chances de enfrentar a competição estrangeira. Entre as políticas de estímulo ao desenvolvimento tecnológico, incluem-se a ampla oferta de financiamento a baixo custo, a concessão de subsídios para o esforço de $\mathrm{P} \& \mathrm{D}$ e diversas iniciativas visando aproximar as empresas das universidades e das instituições de pesquisa ${ }^{26}$. O esforço para ampliar a capacidade tecnológica é captado por indicadores que, ao mensurar o grau de comprometimento dos governos com a política tecnológica, colocavam a China bem à frente de Brasil e México, embora bem atrás de países como Estados Unidos e Coréia do Sul. Indicadores de infraestrutura econômica, que buscam mensurar a presença de instituições físicas, humanas, organizacionais e econômicas com capacidade de

\footnotetext{
25 No entanto, o contexto atual tem outros condicionantes, que podem, como explorado adiante, implicar dificuldades e desafios.

26 Grande parte do esforço de P\&D é feito pelas empresas, destacando-se o esforço para a adaptação da tecnologia importada e a incorporação de técnicas intensivas em mão de obra (NAUGHTON, 2007).
}

influenciar o desempenho tecnológico, colocavam a China em posição intermediária entre os líderes (Japão e Estados Unidos) e outros países emergentes (PORTER et alii, 2007).

Posição similar é alcançada nos índices de infraestrutura tecnológica, que captam as instituições específicas voltadas a desenvolver, produzir e comercializar tecnologia. A China obteve um índice de 60, tendo ficado pouco atrás de Reino Unido, França e Alemanha, enquanto o Japão e os Estados Unidos, os líderes, obtiveram 70 e 95. O melhor resultado foi obtido na capacidade de produção e de exportação de bens de alta tecnologia. Em um índice relativo à produção, a China avançou de 32,8 em 1996 para 85,2 em 2007, ficando apenas atrás dos Estados Unidos. No índice relativo às exportações, a China ultrapassou, inclusive, os Estados Unidos (idem). Trata-se de um avanço, mas que deve ser relativizado por ter sido alcançado, em grande parte, pela atração de firmas estrangeiras. É importante saber o que fica na China e o impacto sobre a capacidade de inovação (CHEN \& CHEN, 2009).

Enfim, deve-se destacar que o objetivo de avançar na capacidade tecnológica vem sendo permanentemente fortalecido. Os gastos de P\&D em proporção do PIB passaram de 1,23\% em 2004 para $1,75 \%$ em 2010, de modo que, em 2011, a China passou a ser o segundo país a mais gastar em P\&D em termos absolutos. Avanços significativos foram também alcançados na produção de artigos científicos, em que a participação chinesa na produção mundial passou de $2 \%$, em 1995 , para $6,5 \%$ em 2004 e $11 \%$ em 2009 (JACQUES, 2012, p. 217).

O esforço de avançar no campo industrial e tecnológico remete a uma questão central: a efetividade das medidas de política industrial no atual estágio do capitalismo. A situação encontrada em vários setores é a de liderança absoluta de grandes empresas multinacionais, que possuem marca forte, controlam amplas frações de mercado e investem fortemente em P\&D. Em diversos indicadores, como volume de vendas e de receita e número de patentes, essas empresas encontravam-se muito a frente de seus competidores. Em diversos setores analisados por Nolan (2005, p. 38), a participação das empresas chinesas nas vendas mundiais ou no esforço de P\&D estava bem abaixo à das líderes globais. Em 
2001, a China tinha apenas 11 representantes entre as 500 maiores empresas listadas pela revista Fortune, não possuindo nenhuma empresa entre as 250 mais competitivas ou entre as 300 que mais investiam em P\&D. Naquele momento, e a despeito de anos de iniciativas ligadas à política industrial, a distância em relação às líderes mundiais estava aumentando.

Esse quadro teve alterações significativas no decorrer da década de 2000, com a China obtendo 29 representantes entre as 500 maiores empresas em 2008, 37 em 2009 e 46 em 2010 (CNN MONEY, 2012) $)^{27}$. Algumas dessas empresas mostraram-se bem-sucedidas no registro de patentes e na consolidação da marca; muitas passaram, nos últimos anos, a adotar estratégias mais agressivas, internacionalizando-se e adquirindo empresas e centros de $\mathrm{P} \& \mathrm{D}$ no exterior $(\text { idem })^{28}$. Jacques (idem) considera que o avanço internacional das empresas chinesas é uma questão de tempo. Além de já terem consolidado posição de liderança em setores como informática, eletrônica de consumo e telecomunicações, as empresas chinesas estariam próximas das líderes em nichos como maquinaria de construção, máquinas ferramentas, automóveis e engenharia elétrica.

Em contraposição, muitas empresas chinesas encontram dificuldades para inovar e mostram-se ainda muito dependentes do mercado interno. Em geral, a capacidade de inovação na China é baixa, no que se constitui um grande desafio do modelo chinês (YAO \& MORGAN, 2008). Assim, ainda não é possível ser conclusivo em relação ao grau em que as empresas chinesas serão bem-sucedidas na capacidade de enfrentar os líderes globais. Há espaço para análises similares à feita por Nolan (2005), acompanhando os avanços das empresas chinesas quanto à capacidade de conquistar mercados internacionais e de inovar. Trata-se de uma questão central para o modelo chinês, ligada à capacidade de avançar na capacidade tecnológica e de produzir campeões nacionais no estágio atual do capitalismo.

Outro aspecto sensível diz respeito aos impactos do grau de intervenção do

\footnotetext{
27 A grande parte dessas empresas é estatal.

28 Como conseqüência, o investimento das firmas chinesas no exterior somou US\$ 70 bilhões em 2010.
}

Estado chinês nas decisões econômicas, que transcende aquele verificado nos exemplos clássicos de Developmental States, em que a demarcação entre o Estado e as empresas era muito mais clara (EVANS, 2004). Na China, os bancos ainda são, em grande parte, estatais, e o Estado mantém um grande controle sobre a alocação dos fluxos financeiros. Da mesma forma, o Estado mantém o controle de grande parte das empresas. Apesar das medidas para estimular a autonomia das empresas estatais e, mesmo, da tentativa de criar-se uma holding dessas empresas, há ainda grande discrição e intervenção do partido comunista e da burocracia. Essa intervenção implica, em algumas ocasiões, a adoção de ações voltadas a fortalecer as empresas e a enfrentar adversidades. Mas, de outro lado, tende a fazer que considerações de outra ordem, ligadas ao interesse do Partido Comunista, interfiram na operação das empresas, tendendo a afetar negativamente a eficiência e a competitividade ${ }^{29}$. Constata-se, no entanto, certo grau de pragmatismo, de forma que os grupos escolhidos para serem campeões nacionais tendem a ser protegidos de intervenções indevidas (NAUGHTON, 2007).

\section{OS GRANDES DESAFIOS}

Apesar dos resultados favoráveis em termos de crescimento econômico e de redução da pobreza, o modelo econômico chinês ainda provoca dúvidas e apreensões. Muitas das reformas estão ainda incompletas e tanto o sistema empresarial como o financeiro apresentam fragilidades. Falta um sistema adequado de direitos de propriedade, o que leva os críticos a duvidarem da persistência do bom desempenho assim que forem superadas as primeiras e mais fáceis fases de crescimento. Dúvidas também aparecem em relação à forte intervenção do Estado na economia. Acredita-se que a recusa do Partido Comunista em abrir mão de parte do poder tende a impedir que o processo de reformas tenha continuidade (PEI, 2006). Enfim, há os problemas ligados à desigualdade crescente e às altas taxas de pobreza ainda prevalecentes. Os problemas sociais são mais sérios quando se consideram as características

\footnotetext{
29 Além de inúmeros casos de corrupção, são comuns os casos em que objetivos de outra ordem interferem no funcionamento das empresas. Um bom exemplo são as medidas de protecionismo local (NOLAN, 2005; PEI, 2006).
} 
rígidas do sistema político, com pouca capacidade de absorver as tensões e as fontes de oposição ao regime.

Inicialmente, deve-se destacar que o contexto institucional chinês não é o mais favorável para o funcionamento de uma economia de mercado. Não existem bons direitos de propriedade, o poder Executivo é muito autônomo, não há um sistema de "checks and balances", o poder Legislativo tem pouco poder e o poder Judiciário não é independente (idem). Assim, o risco regulatório na China é considerado muito alto. No entanto, esse não tem sido um obstáculo para os investimentos estrangeiros, o que se explica pelas altas perspectivas de lucro, pela velocidade da expansão do mercado e pelo fato de que a quebra de contratos, apesar de um risco em potencial, não ter sido a regra ${ }^{30}$.

Há um grande atraso também no sistema de direitos de propriedade intelectual e no registro de patentes, com a freqüente ocorrência de casos de pirataria. As empresas que investem na China sabem que a probabilidade de terem seus produtos copiados é elevada, todavia não podem ficar fora desse mercado. Deve-se destacar que, embora essas práticas possam ajudar empresas locais a aproximarem-se das concorrentes, tendem também a inibir maiores investimentos, inclusive de firmas multinacionais, em P\&D. Um bom exemplo são as firmas norte-americanas, cujos investimentos em $\mathrm{P} \& \mathrm{D}$ na China são muito superiores à média dos investimentos fora dos Estados Unidos, mas que encontram na falta de bons direitos de propriedade um fator que inibe novos investimentos ${ }^{31}$.

Outra característica indesejada, ligada ao grau de discrição da burocracia, é a alta corrupção. As relações econômicas são ainda muito baseadas nas práticas de guanxi, redes pessoais que são a base

\footnotetext{
30 Entre as vantagens da China em termos institucionais encontra-se o baixo custo de fazer negócios, ilustrado pelo baixo tempo de liberalização das alfândegas, muito inferior à média dos países em desenvolvimento.

31 Segundo Naughton (2007, p. 364), as empresas americanas gastam, na China, 9,2\% do valor adicionado em $\mathrm{P} \& \mathrm{D}$, enquanto a média de seus investimentos no exterior é de apenas 3,3\%. Também as firmas chinesas são prejudicadas pela pirataria, que implica rápida expansão da oferta e queda das margens de lucro.
}

para a efetivação de vários negócios, para a obtenção de serviços públicos e para o acesso ao financiamento. Essas práticas vão na direção contrária da presença de regras impessoais, necessárias para o bom desempenho da burocracia e de uma economia de mercado. Nesse sentido, avaliações da organização não-governamental Transparência Internacional colocam a China como um dos países mais corruptos do mundo ${ }^{32}$. Em um ranking internacional, o país obtém uma posição muito ruim em relação a inúmeros indicadores, incluindo qualidade da governança, capacidade regulatória, transparência, estabilidade política, prevalência da lei e "voz e accountability". Em alguns desses indicadores, a China esteve em companhia de países muito atrasados institucionalmente, entre os quais Nicarágua, Indonésia e Nigéria. Em "voz e accountability", a China esteve à frente apenas de estados muito repressivos, como Vietnã, Arábia Saudita e Afeganistão (idem, p. 5-6).

A forte ingerência estatal e a falta de contrapontos institucionais têm inúmeros efeitos negativos. A preservação de monopólios e o forte controle estatal implicam baixa produtividade e atraso em alguns setores, enquanto a não dissociação entre Estado e economia resulta em grande influência do partido nas operações das empresas estatais, muitas vezes em prejuízo da eficiência ${ }^{33}$. A força do poder Executivo, por sua vez, não facilita necessariamente a adoção de políticas adequadas, dado que sua capacidade de ação tende a ser negativamente afetada pelos conflitos interburocráticos, pela ingerência do partido e pelos conflitos existentes entre o governo central e os governos locais (SUN, 2007). Um ótimo exemplo são as medidas de protecionismo local, que incluem proibições para a compra de mercadoria de outras localidades, para a venda de matérias-primas e para a saída de capital. Essas medidas, além de prejudicarem a consolidação do mercado interno, provocam a duplicação do

\footnotetext{
32 No Índice de Percepção de Corrupção (Corruption Perception Index) de 2010, a China ficou em $78^{\circ}$ lugar, em um total de 91 países (TRANSPARENCY INTERNATIONAL, 2010).

33 Segundo Pei (2006), apesar das reformas, grande parte dos membros do partido que compunham a administração anterior continua a ocupar postos importantes na direção das empresas estatais.
} 
investimento, tornando a estrutura produtiva de cada província muito similar à estrutura geral da economia chinesa (PEI, 2006). Essa duplicação, além de provocar a acumulação de capacidade ociosa, inibe os efeitos positivos que poderiam ser obtidos com a especialização produtiva e com o comércio entre as províncias.

Às dificuldades econômicas somam-se os abusos oriundos dos limites em garantir a "prevalência da lei" (rule of law). São inúmeros os relatos de abusos de poder e de violação de direitos, acompanhados da falta de canais de participação e de defesa para os indivíduos. As cortes são inefetivas, fortemente politizadas e corruptas (KYNGE, 2007). A imprensa é controlada e a sociedade civil está muito precocemente organizada. Pei (2006) mostra que muito pouco tem avançado na direção de ampliar os direitos individuais. Ao contrário, a opção do partido tem sido por fortalecer sua capacidade repressiva e de cooptação dos grupos opositores. Nesse sentido, é notável o êxito em impedir que o grande número de protestos sociais, que reúnem freqüentemente dezenas de milhares de pessoas, consolide-se como movimentos organizados capazes de ameaçar o regime.

Pei (idem), usando o referencial desenvolvido por Douglas North, acredita que um dos problemas críticos da China é que o conjunto de direitos de propriedade que maximiza os interesses dos governantes (os membros do Partido Comunista) não é o mesmo que tende a favorecer o melhor desenvolvimento econômico. As principais reformas foram feitas nos anos de 1980, as quais, apesar das transformações econômicas e sociais, não tiveram continuidade na década seguinte. Monopólios foram mantidos em vários setores, incluindo a comercialização de produtos agrícolas, o setor de telecomunicações e o sistema financeiro. A despeito do mau desempenho verificado nesses setores, a liberalização e a entrada de novos participantes continua vetada. Segundo Pei (idem), é ingênuo acreditar que as transformações econômicas tendem a favorecer transformações políticas. $\mathrm{O}$ enriquecimento econômico tende a aumentar os recursos para cooptar adversários e o interesse para preservar o controle. Em contrapartida, a relutância em reformar tende a ampliar as fontes de ineficiência e a agravar algumas tensões, podendo pôr em risco o regime.

$\mathrm{O}$ argumento de Pei, apesar de profícuo, precisa ser contraposto às especificidades do Estado desenvolvimentista chinês, bastante diferente dos estados absolutistas analisados por Douglas North. As autoridades chinesas aprenderam com outras experiências e demonstraram grande habilidade em conduzir o processo de transição. $\mathrm{O}$ caráter desenvolvimentista, assim como certa capacidade das lideranças, explica a preservação da estabilidade econômica e a adoção de políticas econômicas favoráveis ao desenvolvimento dos negócios. Notase também, nos últimos congressos do partido comunista, o reconhecimento de dificuldades e a identificação de direções para corrigir os desequilíbrios $^{34}$. Trata-se, portanto, da contraposição de possibilidades, amparadas por diferentes teorias de Economia Política. A teoria do neoinstitucionalismo econômico aponta para as dificuldades que tendem a surgir em face das diferenças entre os interesses das lideranças e as necessidades do modelo. Já a teoria ligada aos estados desenvolvimentistas destaca o peso do Estado chinês, sua tradição e unidade milenares e sua capacidade de conduzir o processo, em um modelo bastante diferente do capitalismo ocidental (JACQUES, 2012).

Outro grande desafio advém do setor financeiro. Apesar dos avanços, as reformas foram incapazes de melhorar significativamente a capacidade de avaliação de risco e de alocação de capital para os setores com maior potencial econômico. Há ainda muitos critérios políticos atrelados à concessão de empréstimos ${ }^{35} \mathrm{e}$, apesar de vultosos programas de saneamento adotados para o sistema financeiro, o número de empréstimos podres, com poucas chances de serem pagos, é muito elevado ${ }^{36}$. Pouco

\footnotetext{
34 Essa via permite interpretar o processo chinês como de "transição vinda de cima", em que o Partido Comunista implementou reformas visando dinamizar a economia e evitar que uma crise econômica e social levasse o regime à derrocada (GUIMARÃES, 2009b). Resta saber até que ponto o Partido Comunista estará disposto a ir, assim como sua capacidade de detectar e implementar as mudanças necessárias.

35 Apesar de o setor privado ter grande participação na geração de emprego, sua participação no investimento e no crédito é muito menor, sendo um indicativo do viés que marca o sistema financeiro.

36 Segundo Naughton (2007), a proporção de empréstimos podres teria, no final da década de 1990, alcançado
} 
transparente, o sistema é caracterizado por inúmeros casos de favorecimento e de corrupção. A cobrança de propinas é freqüente, encarecendo o custo dos empréstimos (NAUGHTON, 2007). Há também problemas de regulação, o que em um contexto de liquidez excessiva, como tem ocorrido nos últimos anos, tende a favorecer a formação de bolhas e o risco de perdas no sistema financeiro. Em tal contexto, destacam-se os riscos que os problemas do sistema financeiro podem acarretar à saúde da economia chinesa e ao projeto de incorporar centenas de milhões de pessoas à economia de mercado (NOLAN, 2004). Apesar de o sistema financeiro chinês ser em grande parte voltado para práticas de empréstimo, o que explica seu baixo envolvimento no cassino internacional que levou à crise financeira de 2008, o risco não deve ser subestimado ${ }^{37}$.

Segundo os críticos, as dificuldades do sistema financeiro têm fortes implicações na qualidade do investimento. $\mathrm{O}$ sistema financeiro direciona grande parte dos recursos para as empresas estatais, que, em face da abundância de recursos, investem de maneira arrojada e efetivam investimentos pouco viáveis e de baixa rentabilidade. Tal situação tende a provocar excesso de capacidade em alguns setores e a comprometer a capacidade de investimento futuro $^{38}$. Em síntese, o fácil acesso ao crédito, a grande capacidade de investimento e a baixa capacidade de regulação tendem a enfraquecer o modelo econômico, podendo acarretar crises econômicas e financeiras que colocariam em risco os avanços econômicos e sociais.

Outra fonte de dificuldades relaciona-se ao aumento da desigualdade social e à proporção ainda

$40 \%$ do total de empréstimos. Em conseqüência de um programa de saneamento que custou U\$ 300 bilhões, essa proporção caiu para $10,5 \%$ em 2005 . Essa tem sido uma constante nos últimos anos: aumento dos empréstimos podres, intervenção e saneamento, seguido por novo ciclo de empréstimos podres.

37 Na crise de 1997, muitas instituições chinesas sucumbiram devido à grande especulação. Há também várias menções à formação de bolhas tanto no mercado de ações como no setor imobiliário (NOLAN, 2004).

38 Esse é o ponto destacado por Martin Wolf (2009), que acredita que as taxas de investimento na China são muito altas tanto para seu nível de renda per capita como para o nível de crescimento do PIB, indicando uma relação capital-produto muito alta. muito alta de pobres. Apesar da forte redução da pobreza após 1978 , deve-se destacar que esta redução não foi contínua. Entre 1981 e 1987, a pobreza caiu pela metade, resultado essencialmente da reforma rural, que deu aos agricultores maior liberdade para comercializar a produção. Entre 1987 e meados da década 1990, a diminuição da pobreza estancou, voltando a cair, mesmo que a um ritmo reduzido, entre $1996 \mathrm{e}$ 2001. A partir de 2001, a pobreza passou a declinar de modo mais forte, resultado dos efeitos da entrada da China na $\mathrm{OMC}$ e da maior atenção à questão social (DOLLAR, 2007; RAVALLION \& CHEN, 2007).

Apesar da forte queda, a proporção de pobres é ainda elevada. A China ainda possui uma grande proporção de população no campo, em torno de 700 milhões de pessoas, sendo que uma alta proporção (acima de 50\%, de acordo com a linha de pobreza adotada) ainda vive abaixo da linha de pobreza. Essa alta persistência da pobreza, a despeito das altas taxas de crescimento, está diretamente relacionada ao aumento da desigualdade. Entre 1983 e 2002, o Índice de Gini passou de 0,28 para 0,447 , tornando a desigualdade na China superior à média dos países de renda média (DOLLAR, 2007). Parte do aumento da desigualdade pode ser explicada pela maior diferenciação típica de uma economia de mercado e pelas transformações que marcam as primeiras etapas do desenvolvimento ${ }^{39}$. No entanto, o aumento da desigualdade foi também decorrência das políticas adotadas.

Existe grande desigualdade regional na China, ampliada pela criação das ZEEs e pelo conseqüente estímulo às zonas costeiras. As regiões litorâneas atraíram quase a totalidade dos investimentos estrangeiros e foram as grandes beneficiárias do processo de abertura. As províncias do centro e do oeste sofreram devido aos problemas de infraestrutura, que as isolavam em relação às áreas em transformação. Como conseqüência, a disparidade de renda per capita entre as províncias ampliou-se, com a desigualdade entre a mais rica e a mais pobre passando de 7,3 vezes em 1990

\footnotetext{
39 Nos estágios iniciais, todos são igualmente pobres, uma vez empregados em atividades de baixa produtividade. Com as transformações e o surgimento de diferenciais de produtividade e de oportunidades, a desigualdade tende a ampliar-se, conforme descrito pela curva de Kuznetz.
} 
para 13 vezes em 2003, número muito elevado em qualquer comparação internacional (HORTA, 2009; ZHU \& WAN, 2012).

O impacto das desigualdades regionais é ainda mais sério quando se considera a forma muito descentralizada de financiamento e de execução dos gastos sociais, o que leva as províncias mais ricas a gastarem muito mais do que as mais pobres ${ }^{40}$. O resultado é que as regiões e as localidades mais pobres não obtêm os recursos necessários para prover bons serviços de educação e saúde, tendo, em muitos casos, de cobrar por esses serviços. Como grande parte da população é incapaz de pagar, não tem acesso a esses serviços ou tem-los em qualidade baixa ${ }^{41}$. Portanto, o grau de descentralização produz grande desigualdade no acesso à saúde, à educação e a outros serviços básicos, o que contribui para ampliar o retorno da educação e as desigualdades de renda. Isso é bem ilustrado pelo aumento do retorno salarial de um ano a mais de estudo, que entre 1988 e 2003 teria crescido de $4 \%$ para $11 \%$, reflexo também das oportunidades abertas pela diversificação da economia (DOLLAR, 2007).

Outra fonte expressiva de desigualdades é aquela existente entre o campo e a cidade. As diferenças de renda urbano-rural oscilaram muito, tendo se reduzido após a reforma rural, mas voltando a crescer subseqüentemente. Tais diferenças são criticamente afetadas por certas políticas, com destaque para as restrições para a migração entre o campo e a cidade e para a relutância em conceder o direito de propriedade das terras à população rural ${ }^{42}$. Estima-se que um montante próximo a 150 milhões de pessoas deixam anualmente o campo em direção às cidades em busca de trabalho temporário. A maior parte

40 Segundo Dollar (2007), o gasto social por habitante tende a ser oito vezes maior na província mais rica em relação à mais pobre, diferença que no Brasil é de 2,3 vezes. As diferenças são maiores em nível subprovincial.

41 A taxa de freqüência à escola, que é de $100 \%$ na província mais rica, era de $40 \%$ na mais pobre. Essas deficiências vêm levando o governo a ampliar significativamente os recursos para educação e saúde nas áreas mais pobres. Em 2006, foi eliminada a exigência de taxas para a educação da população carente (idem)

42 Como conseqüência, a diferença de renda entre as zonas urbana e rural era de três para um, muito alta para os padrões internacionais. vive em condições clandestinas, não possuindo o registro (hukou) necessário para ter acesso a uma série de serviços públicos. Tornam-se, portanto, cidadãos de segunda classe, vivendo em moradias precárias e sem acesso aos serviços de educação, saúde e previdência. Sofrem também discriminação quanto ao acesso a postos de trabalho. Assim, o sistema de hukou e suas restrições contribuem para a desigualdade de renda e de oportunidades (HORTA, 2009) ${ }^{43}$. A população imigrante, vivendo em condições precárias, constitui uma fonte de protestos e de instabilidade social.

Vale destacar que as dificuldades sociais foram fortemente agravadas pelo grande número de pessoas demitidas, aproximadamente 30 milhões, resultado do processo de reestruturação das empresas estatais. Trata-se de pessoas que possuíam estabilidade no emprego e acesso a serviços de proteção social. Esse contingente inclui grande parte de trabalhadores mais velhos e de baixa escolaridade, com dificuldades para reinserirem-se no mercado de trabalho. A situação dos demitidos implicou forte aumento dos gastos em pensões, serviços de saúde e habitação. No geral, as dificuldades são infladas pelo caráter precário do sistema de seguridade social. Após as reformas, a seguridade social passou a assumir a forma de um programa de seguros, incluindo seguro para idosos, seguro desemprego e seguro médico. O problema é que os mais pobres não podem pagar pelos mesmos, ficando desprotegidos e arcando com grande parte dos gastos (ZHU \& WAN, 2012). Segundo Leung (2006), em 2003 apenas $40 \%$ dos trabalhadores urbanos eram cobertos por seguro-desemprego e apenas $45 \%$ participavam de programas de aposentadoria ${ }^{44}$. Dados para 2000 apontavam que $44 \%$ das mulheres idosas e $51 \%$ das pessoas acima de 80 anos não contava com aposentadoria ${ }^{45}$.

\footnotetext{
43 O sistema de hukou cumpriu seu papel ao possibilitar um ritmo menos intenso de migração e de crescimento das cidades. No entanto, tem sérios problemas. Em fevereiro de 2010, 13 jornais lançaram um editorial conjunto defendendo reformas. Há, no entanto, um enorme custo financeiro oriundo da extensão de direitos sociais a 150 milhões de pessoas (JACQUES, 2012, p. 198).

44 Os números para a área rural eram muito piores.

45 Segundo estimativas, apenas $20 \%$ dos 700 milhões de integrantes da população economicamente ativa tinha acesso à previdência (DESAFIOS DO MILAGRE CHINÊS, 2005).
} 
Os problemas levantados apontam para políticas com potencial para a diminuição da desigualdade. Inicialmente, destacam-se os investimentos em infraestrutura e o estímulo às atividades econômicas das regiões mais pobres, incluindo uma política adequada de preços agrícolas. Em 1999, o governo lançou a "Grande estratégia de desenvolvimento para o Oeste", passando, a partir de então, a elevar significativamente as transferências e os investimentos para as províncias mais pobres, além de estimular os investimentos de empresas multinacionais.

Em segundo lugar, encontra-se a necessidade de melhorar a qualidade e o acesso a serviços de educação e saúde, diminuindo as diferenças entre as províncias. A partir do XVII Congresso do Partido Comunista, em 2007, o governo vem reforçando significativamente os gastos em saúde, educação e transferências de renda para famílias pobres. Em 2008, o gasto com educação subiu 45\% e em 2009 o governo lançou uma ambiciosa reforma no sistema de saúde, visando prover seguro básico para $90 \%$ da população (JACQUES, 2012). Vem havendo também um forte aumento dos gastos com o programa de subsistência básica, que em 2009 passou a cobrir 23 milhões de habitantes da zona urbana e 42,8 milhões na zona rural (GAO et alii, 2011). Nesse sentido, tem sido enfática a decisão de corrigir alguns dos aspectos mais negativos do modelo econômico. No entanto, são substanciais os desafios, exigindo um acompanhamento cuidadoso das políticas e de seus resultados.

A esses desafios, somam-se outros como os riscos ambientais. A China possui algumas das cidades mais poluídas do mundo, com fortes custos em termos de mortes, desmatamento e prejuízos à economia. Esses problemas estão relacionados às características tanto do modelo econômico, muito intensivo em capital e energia, como da matriz energética, muito dependente do carvão, o que em um país com tal ritmo de crescimento implica impactos explosivos. $\mathrm{O}$ governo vem estimulando amplamente o desenvolvimento de fontes de energia limpas, mas os desafios são enormes.

\section{CONCLUSÕES}

A China, dado o acelerado processo de transformação econômica e social, constitui um laboratório rico para o estudo de várias áreas das
Ciências Sociais. Este artigo focalizou uma dessas áreas, ligada ao modelo econômico e à relação muito particular desenvolvida entre o Estado e o mercado. $\mathrm{O}$ intenso desenvolvimento econômico verificado nos últimos 30 anos deveu-se às potencialidades representadas pela liberalização das forças de mercado, mas dependeu também do grau de capacidade estatal, responsável pela correção das falhas de mercado, pela condução do processo de transição e pelas medidas de estímulo à atividade econômica. Apesar dos resultados alcançados, essa combinação tem implicações e armadilhas.

O modelo chinês replica em diversas situações as características dos Developmental States existentes em países da Ásia em períodos anteriores. A capacidade de ação do Estado e a sua força em relação aos grupos sociais são fundamentais para esclarecer o êxito da transição, assim como a constituição dos pré-requisitos para o funcionamento de uma economia de mercado. Destaca-se também a capacidade de as autoridades chinesas fomentarem certos setores e empresas, preservarem bons fundamentos econômicos e garantirem a ordem social. A especificidade chinesa está em apresentar tal grau de intervenção em um contexto bem particular do capitalismo, marcado pela maior integração econômica e financeira e por menores graus de liberdade conferidos à intervenção estatal.

Há, no entanto, o outro lado da intervenção estatal: as relações entre o Estado e a economia são fluidas; há grande imbricação entre os interesses do partido e a gestão das empresas; faltam instituições que garantam o respeito à lei e aos direitos dos cidadãos, sendo a corrupção uma prática recorrente; o poder Executivo é muito forte e o poder Judiciário não é independente; por fim, falta uma estrutura de direitos de propriedade capaz de proteger os investidores. A isso se somam as fontes de ineficiência decorrentes de monopólios em certos setores e as deficiências do setor financeiro, marcado por critérios políticos na concessão de financiamento, por grande acumulação de empréstimos podres e por uma estrutura precária de regulação.

Devido às suas particularidades, a China vem conseguindo frear o ritmo da abertura financeira e conservar certos padrões de intervenção. Há, no entanto, dúvidas quanto à capacidade de preservar esse poder, sem falar das vantagens de 
tornar o remimbi uma moeda internacional. Uma vez consumado um maior ritmo de abertura e de liberalização financeira, surgem apreensões relativas às fraquezas do sistema financeiro e do sistema de direitos de propriedade. Deve-se lembrar os casos do Japão e da Coréia do Sul, em que as pressões por liberalização mostraram-se letais para o modelo econômico, provocando fortes custos econômicos e sociais (GUIMARÃES, 2009a).

Existe, portanto, uma contraposição de fatores: de um lado, há a força do Estado chinês, voltado para consolidar a capacidade produtiva e tecnológica e para avançar com os interesses externos, iniciativas que vêm se fortalecendo nos últimos anos. Após a crise de 2008, as empresas chinesas passaram a adotar estratégias mais agressivas e a adquirir ativos em várias partes do mundo. Ao mesmo tempo, a China passa a estreitar os laços econômicos e a ampliar a sua influência nos diversos continentes, o que vem sendo alcançado por meio de um grande aumento nos investimentos, nos empréstimos e na ajuda financeira a inúmeros países (JACQUES, 2012). Por outro lado, ainda não se pode descartar os constrangimentos e as exigências levantados pela maior complexidade da economia de mercado, assim como as demandas por direitos e por participação que podem surgir da nova estrutura social. E há também os riscos relacionados a crises financeiras, à acumulação de capacidade ociosa e ao aumento do desemprego, que podem ter impactos negativos na preservação da ordem social.

O caso chinês aponta também para as possibilidades e potencialidades da política industrial no momento atual do capitalismo. Há indicações de avanços na base produtiva e tecnológica, destacando-se, além do esforço empreendido, a capacidade de enquadrar o capital estrangeiro e de produzir campeões nacionais com potencial de competição internacional. No entanto, prevalecem dúvidas sobre o grau de sucesso tanto na capacidade de inovação como na de produzir empresas aptas a enfrentar as líderes mundiais nos respectivos setores. Esse aspecto aponta para a necessidade de monitorar o avanço das empresas chinesas tanto na capacidade de registrar patentes como de disputar os mercados com as empresas multinacionais.

Os temas tratados neste artigo transcendem a situação da China. As formas de interação entre o mercado e o Estado é um tema essencial da Economia Política desde as suas origens. Um tema derivado dessa relação é o estudo dos Developmental States e das condições em que a intensa intervenção estatal tende a ser profícua. Isso aponta para os aspectos positivos e negativos da intervenção estatal, incluindo tanto a capacidade de promover certos setores como as dificuldades advindas do conflito interburocrático e da adoção de práticas de patronagem e "rent seeking". O exemplo chinês levanta também a questão da relevância das instituições econômicas e da garantia dos direitos de propriedade, assim como a relação entre as transformações econômicas e as mudanças políticas, indagando sobre as circunstâncias em que as elites políticas estariam dispostas a adotar reformas que impliquem abrir mão de parte do poder.

O caso chinês é também muito caro ao estudo das relações internacionais, ilustrando interações entre as iniciativas de política externa e a perseguição de objetivos econômicos. Nesse sentido, as práticas de negociação com o capital estrangeiro e a adoção de medidas de política industrial e tecnológica podem trazer lições para os países em desenvolvimento. Outra questão diz respeito ao impacto da ascensão da China sobre o emprego nos países desenvolvidos, assim como às medidas de retaliação que podem ser adotadas e seus impactos na ordem internacional.

Em 2007, o XVII Congresso realizado pelo Partido Comunista destacou várias deficiências enfrentadas pelo modelo chinês, enfatizando a alta dependência das exportações e do investimento, a baixa capacidade de inovação, a alta desigualdade de renda, a precariedade da seguridade social e os impactos sobre o meio ambiente (YAO \& MORGAN, 2008). Um amplo conjunto de medidas vem sendo adotado visando enfrentar essas dificuldades. A direção teria sido fortalecida pelo Congresso do Partido Comunista de 2011, anunciando um plano de reformas extremamente ambicioso voltado a promover a tecnologia verde, a fortalecer os salários e as aposentadorias e a aproveitar melhor o potencial do amplo mercado interno (JAGUARIBE, 2012). Assim, uma direção essencial é monitorar o avanço, os obstáculos e os resultados dessas políticas. Trata-se de um estudo de caso privilegiado, que envolve inúmeras questões relativas aos estados desenvolvimentistas e à capacidade do Estado, além de várias políticas públicas e importantes dimensões do desenvolvimento econômico e social. 
Alexandre Queiroz Guimarães (alexandre.queiroz@fjp.mg.gov.br) é Doutor em Ciência Política pela University of Sheffield (Reino Unido), Professor da Escola de Governo da Fundação João Pinheiro (FJP) e Professor de Economia da Pontifícia Universidade Católica de Minas Gerais (PUC-MG).

\section{REFERÊNCIAS BIBLIOGRÁFICAS}

AMARAL, J. L. 2005. Os vetores do crescimento da China. Gazeta Mercantil, São Paulo, 20.jul. Disponível em: http:// raceadmv3.nuca.ie.ufrj.br/buscarace/Docs/ jlamaral1.pdf. Acesso em: 1.mar.2013.

ANTUNES, L.; STEFANO, F. \& MARANHÃO, T. 2009. A China encara a crise. Exame, São Paulo, n. 937, 19.fev. Disponível em: http:// exame.abril.com.br/revista-exame/edicoes/ 0937/noticias/china-encara-crise-422443. Acesso em: 1.mar.2013.

CHANG, H. J. 2006. The East Asian Development Experience. The Miracle, the Crisis and the Future. Penang: Third World Network.

CHEN, Y. \& CHEN, J. 2009. The Impact of FDI on Regional Technological Capabilities: evidence from China. Journal of KnowledgeBased Innovation in China, v. 1, n. 2, p. 143158.

CUNHA, A. M. 2008. A ascensão da China à condição de potência econômica: há algo de novo no modelo asiático? Trabalho apresentado no XIII Encontro Nacional de Economia Política, realizado em João Pessoa, de 20 a 23 de maio. Digit. Disponível em: http:// www.anpec.org.br/encontro2008/artigos/ 200807091508220-.pdf. Acesso em: 1.mar.2013.

CUNHA, A. \& ACIOLY, L. 2009. China: ascensão à condição de potência global. Características e implicações. In: CARDOSO JR, J.; ACIOLY, L. \& MATIJASCIC, M. (orgs.). Trajetórias recentes de desenvolvimento: estudos de experiências internacionais selecionadas. Brasília: Instituto de Pesquisa Econômica Aplicada.

DOLLAR, D. 2007. Poverty, Inequality and Social Disparities During China's Economic Reform. World Bank Policy Research Working Paper, n. 4523, June. Disponível em: http://wwwwds.worldbank.org/external/default/ WDSContentServer/IW3P/IB/2007/06/13/ 000016406_20070613095018/Rendered/PDF/ wps4253.pdf. Acesso em: 1.mar.2013.
EVANS, P. 2004. Autonomia e parceria. Estados e transformação industrial. Rio de Janeiro: UFRJ.

FONSECA, E.G. 1993. Vícios privados, beneficios públicos? A ética na Riqueza das Nações. São Paulo: Companhia das Letras.

GAO, Q.; YOO, J.; YANG, S. \& ZHAI, F. 2011. Welfare Residualism: A Comparative Study of the Basic Livelihood Security Systems in China and South Korea. International Journal of Social Welfare, Hoboken, v. 20, n. 2, p. 113124, Apr.

GEREFFI, G. 2009. Development Models and Industrial Upgrading in China and Mexico. European Sociological Review, Oxford, v. 25, n. 1, p. 37-51. Disponível em: http:// w w w . c g g c . d u k e.e d u/pd f s/ Gereffi_Development_\&_upgrading_in China_\&_Mex_European_Soc_Review_Feb 2009\%5B1\%5D.pdf. Acesso em: 1.mar.2013.

GUIMARÃES, A. 2009a. Estado, instituições e desenvolvimento: o modelo coreano e a interpretação da crise asiática. Revista de Sociologia e Política, Curitiba, v. 17, n. 34, p. 253-269, out. Disponível em: http:// www.scielo.br/pdf/rsocp/v 17 n $34 /$ a18v17n34.pdf. Acesso em: 2.mar.2013.

2009b. A Economia Política do desenvolvimento da China: Estado, mercado e a construção do modelo econômico chinês. Trabalho apresentado no VIII Congresso Brasileiro de História Econômica, realizado na Universidade Estadual de Campinas, de 6 a 8 de setembro. Digit.

HORTA, M. 2009. Pobreza e desigualdade no milagre chinês. Relatório de pesquisa apresentando ao Fundo de Incentivo a Pesquisa. Belo Horizonte: PUC-MG.

JACQUES, M. 2012. When China Rules the World. The End of the Western World and the Birth of a New Global Order. London: Penguin.

JAGUARIBE, A. 2012. Expansão favorece vários 
produtos do país. Valor Econômico, São Paulo, especial "Rumos da economia", 2.maio. Disponível em: https://conteudoclippingmp. planejamento.gov.br/cadastros/noticias/2012/ 5/2/expansao-favorece-varios-produtos-dopais/. Acesso em: 2.mar.2013.

KYNGE, J. 2007. A China sacode o mundo. A ascensão de uma nação com fome. São Paulo: Globo.

LARDY, N. 2002. Integrating China into the Global Economy. Washington (DC): Brookings.

LEUNG, J. 2006. The Emergence of Social Assistance in China. International Journal of Social Welfare, Hoboken, v. 15, n. 3, p. 188198, July.

MEDEIROS, C. 2004. A Economia Política da internacionalização sob liderança dos Estados Unidos: Alemanha, Japão e China. In: FIORI, J. L. (org.). O poder americano. Petrópolis: Vozes.

NAUGHTON, B. 2007. The Chinese Economy. Transitions and Growth. Cambridge: MIT.

NOLAN, P. 2004. China at the Crossroads. Cambridge: Polity.

2005. Transforming China: Globalization, Transition and Development. London: Anthem.

PEI, M. 2006. China's Trapped Transition: The Limits of Developmental Autocracy. Cambridge (MA): Harvard University.

PEMPEL, T. J. 2005. Introduction: Emerging Webs of Regional Connectedness. In: PEMPEL, T. J. (ed.). Remapping East Asia: The Construction of a Region. London: Cornell University.

PORTER, A.; NEWMAN, N.; XIAO, Y.; JOHNSON, D. \& ROESSNER, J. 2007. High Tech Indicators. Technology-Based Competitiveness of 33 Nations. Report to the Science Indicators Unit. National Science
Foundation. Atlanta: Georgia Institute of Technology.

RALSON, D.; TERPSTRA-TONG, J.; WANG, X. \& EGRI, C. 2006. Today's State-Owned Enterprises of China: Are They Dying Dinosaurs or Dynamic Dynamos? Strategic Management Journal, Hoboken, n. 27, p. 825843. Disponível em: http://ufirc.ou.edu/ publications/enterprises $\% 20 \mathrm{of} \% 20$ china.pdf. Acesso em: 1.mar.2013.

RAVALLION, M. \& CHEN, S. 2007. China's (Uneven) Progress Against Poverty. Journal of Development Economics, Washington (DC), v. 82, n. 1, p. 1-42. Disponível em: http:// siteresources.worldbank.org/PGLP/ Resources/ShaohuaPaper.pdf. Acesso em: 2.mar.2013

ROACH, S. S. 2011. Dez razões para apostar na China. O Estado de S. Paulo, 29.maio. Disponível em: http://www.estadao.com.br/ noticias/impresso,dez-razoes-para-apostar-nachina,725357,0.htm. Acesso em: 1.mar.2013.

SUN, P. 2007. Is the State-Led Industrial Restructuring Effective in Transition China? Evidence from the Steel Sector. Cambridge Journal of Economics, Oxford, v. 31, n. 4, p. 601-624, Apr.

WHITE, S. 2000. Russia's New Politics. The Management of A Ppostcommunist Society. Cambridge: Cambridge University.

WOLF, M. 2009. A ascensão da China. Valor Econômico, São Paulo, 13.abr.

YAO, S. \& MORGAN, S. 2008. On the New Economic Policies Promoted by the 17th CCP Congress in China. The World Economy, Hoboken, v. 31, n. 9, p. 1129-1153, Sep.

ZHU, C. \& WAN, G. 2012. Rising Inequality in China and the Move to a Balanced Economy. China \& World Economy, Hoboken, v. 20, n. 1, p. 83-104, Jan.-Feb.

\section{OUTRAS FONTES}

CNN MONEY. 2012. Global 500. Our Annual Raking of the World's Largest Corporations. Disponível em: http://money.cnn.com/ magazines/fortune/global500/2010/countries/ China.html. Acesso em: 2.mar.2013.
Desafios do milagre chinês. 2005. Valor Econômico, São Paulo, 27.jul.

O enigma da China. 2005. O Estado de S. Paulo, caderno "Opinião", p. 2, 8.jun. 
TRANSPARENCY INTERNATIONAL. 2012.

Corruption Perception Index. Disponível em: http://www.transparency.org/policy_research/ surveys_indices/cpi. Acesso em: 2.mar.2013.

WORLD BANK. 1993. The East Asian Miracle: economic growth and public policy. New York:
Oxford University.

2011. World Development Indicators. Disponível em: http://data.worldbank.org/datac a t a log / w o r ld - d e velopmentindicators?cid=GPD_WDI. Acesso em: 1.mar.2013. 
THE POLITICAL ECONOMY OF THE CHINESE ECONOMIC MODEL: STATE, MARKET AND MAJOR CHALLENGES

\section{Alexandre Queiroz Guimarães}

This article explores certain characteristics of the Chinese model starting from its institutional particularity, the relationship between state and market. The success of the Chinese miracle is related to the liberalization of market forces, but it is also indebted to the role of the Developmental State, which played an important role in the strengthening of productive and technological capacity. However, lack of dividing lines between State and market also implies particular difficulties, manifested through the excessive intervention of the party and deficiencies in the financial and property rights systems. On the one hand, the economy is benefited by the strength of the State and the measures that have been adopted to bolster its international position. On the other hand, there are tensions between a more complex economy and a very specific institutional structure. Another point to be explored lies in the efforts that have been adopted to strengthen industrial and technological capacities, inquiring into the efficacy of industrial policy at the present stage of capitalism. Finally, the article looks at other challenges of the Chinese model, including those of the social arena, discussing how they have been faced.

KEYWORDS: China; Institutions; Development; Developmental State; Political Economy. 

ET LES PRINCIPAUX DÉFIS

\section{Alexandre Queiroz Guimarães}

L'Article explore quelques caractéristiques du modèle chinois à partir de sa particularité institutionnelle, la relation entre 1'État et le marché. Le succès du miracle chinois est très lié à la libéralisation des forces du marché, mais est dû aussi au rôle de l'État de Développement, qui a eu un rôle important dans la transition pour l'économie de marché et contribue encore significativement pour le renforcement de la capacité productive et technologique. Toutefois, le manque de démarcation entre 1'État et le marché implique aussi des difficultés, qui sont manifestées dans l'intervention excessive du parti et dans les faiblesses du système financier et du système de droits de propriété. D'un côté, l'économie est bénéficiée par la force de 1'État et par les mesures adoptées pour renforcer sa position internationale. De l'autre, il y a des tensions entre une économie plus complexe et une structure institutionnelle très spécifique. Un autre point exploré dans l'article, c'est celui des efforts adoptés pour renforcer la capacité industrielle et technologique, en questionnant l'effectivité de la 
politique industrielle dans la phase actuelle du capitalisme. Enfin, l'article travaille d'autres défis du modèle chinois, même dans le domaine social, en soulignant comment 1'on fait face à eux.

MOTS-CLÉS: Chine; institutions; développement; État de développement; Économie Politique. 